
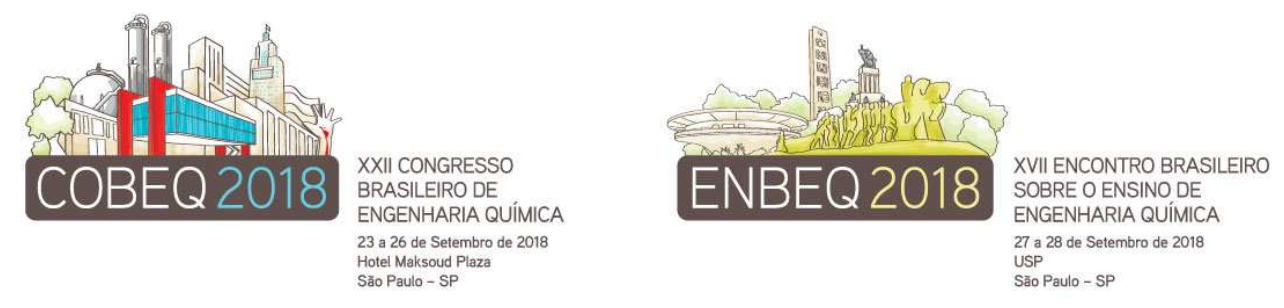

\title{
MARINE MACROALGA PELVETIA CANALICULATA AS A NATURAL CATION EXCHANGER FOR BARIUM REMOVAL
}

\author{
FONTÃO NC ${ }^{1}$, HACKBARTH FV ${ }^{1}$, MAYER DA ${ }^{1}$, MAZUR LP ${ }^{1}$, SOUZA AAU ${ }^{1}$, VILAR \\ VJP $^{2}$ e SOUZA SMAGU ${ }^{1}$ \\ ${ }^{1}$ Laboratory of Mass Transfer, Department of Chemical Engineering and Food Engineering, \\ Federal University of Santa Catarina (UFSC) \\ ${ }^{2}$ Laboratory of Separation and Reaction Engineering - Laboratory of Catalysis and Materials \\ (LSRE-LCM), Chemical Engineering Department, Faculty of Engineering University of Porto \\ (FEUP) \\ E-mail para contato: nataliafontao@gmail.com
}

\begin{abstract}
In this study, Ca-loaded macroalga Pelvetia canaliculata was investigated as a natural cation exchanger for barium removal. A mass action law was able to fit satisfactorily the equilibrium data for the ternary mixture $\left(\mathrm{Ba}^{2+} / \mathrm{H}^{+} / \mathrm{Ca}^{2+}\right)$, resulting in selectivity coefficients of $K_{H}^{B a}=6.88 / 0.41$ and $K_{H}^{C a}=3.08 / 0.03$, for carboxylic/sulphonic groups. In the packed bed column, the service capacity was 237 bed-volumes $(B V)$, treating 14.2 L of influent with a feed concentration of $2.9 \mathrm{mEq} \mathrm{Ba}{ }^{2+/} L$,

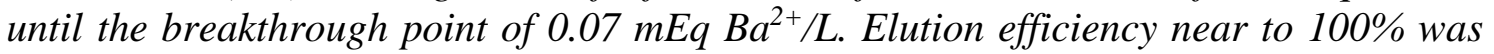
achieved using $5 \mathrm{BV}$ of $1.0 \mathrm{M} \mathrm{HCl}$ in counter-flow direction. A dynamic mass transfer model, considering equilibrium given by the mass action law, linear driving force (LDF) approach to describe the intraparticle mass transfer resistance and the stagnated film resistance described well the breakthrough profiles for all species obtained in a packed bed column.
\end{abstract}

\section{INTRODUCTION}

Barium is a toxic metallic pollutant resulting from various industrial processes, with emphasis on the petrochemical, mining and nuclear industries. Barium contamination causes health damage: nausea, abdominal pain, muscular convulsions, cardiovascular problems, and paralysis of the peripheral nervous system. Therefore, minimizing barium contamination of water and soil sources has become a matter of environmental and public health concern.

In the last decades, the use of marine algae as natural cation exchange resins for heavy metals removal has been successfully highlighted in the literature (Zeraatkar et al., 2016). However, in contrast to what happens with other metals $(\mathrm{Cd}, \mathrm{Cu}, \mathrm{Ni}, \mathrm{Pb}$, and $\mathrm{Zn})$, studies on the use of marine algae for barium removal are scarce. Therefore, the present study aims to contribute to filling this gap.

\section{MATERIALS AND METHODS}



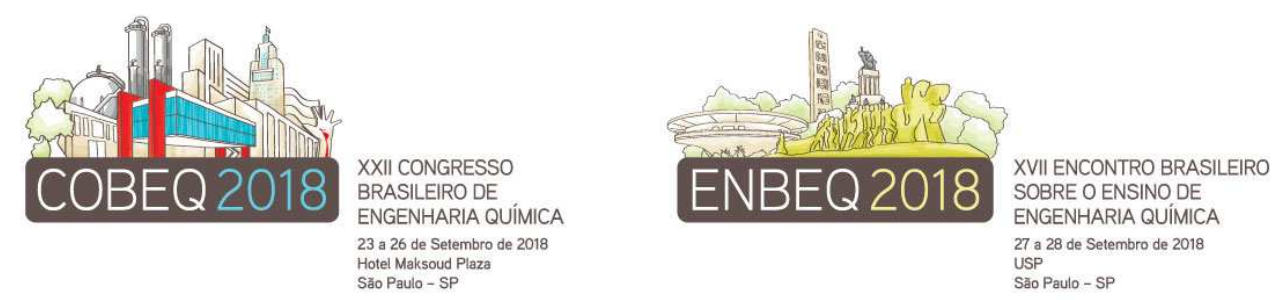

The $P$. canaliculata (brown algae) was collected in Northern coast of Portugal, washed, dried and milled. The protonation of seaweed functional groups followed the procedure reported in Cechinel et al. (2016). Afterwards, the protonated biomass was converted into the calcium form, according to the methodology described by Mazur et al. (2017). This alga was denominated $\mathrm{Ca}$-alga. $\mathrm{Ba}^{2+}$ solutions were prepared by dissolving a weighed quantity of $\mathrm{Ba}\left(\mathrm{NO}_{3}\right)_{2}(99 \%$, Vetec) in ultrapure water.

The equilibrium and kinetic studies were carried out in Erlenmeyer flasks containing $50 \mathrm{~mL}$ of solution and $0.05 \mathrm{~g}$ of Ca-alga under constant stirring $(130 \mathrm{rpm})$ and temperature $\left(25^{\circ} \mathrm{C}\right)$, at $\mathrm{pH} 5.3$. For the $\mathrm{Ba}^{2+}$ equilibrium assays, initial barium concentrations from 5 to $300 \mathrm{mg} / \mathrm{L}$ were in contact with resin $(1 \mathrm{~g} / \mathrm{L}$ ) for a period of $24 \mathrm{~h}$ (time required to reach equilibrium). Batch kinetic studies were performed with barium initial concentration of $200 \mathrm{mg} / \mathrm{L}\left(\left[\mathrm{Ba}^{2+}\right]_{0}\right)$. Samples were collected at predetermined time intervals until equilibrium is reached. At the end of each experimental procedure, samples were filtered and the residual metal concentrations $\left(\mathrm{Ba}^{2+}\right.$ and $\mathrm{Ca}^{2+}$ ) were determined by atomic absorption spectrophotometry (AAS). A mass action law was used to describe the ternary $\left(\mathrm{Ca}^{2+} / \mathrm{H}^{+} / \mathrm{Ba}^{2+}\right)$ equilibrium cation exchange data as described by Mazur et al. (2017). A dynamic mass transfer model, reported in Mazur et al. (2017), was applied to predict the batch kinetic profiles for all species in solid and liquid phases.

An experiment in continuous mode was performed in a column made of borosilicate glass ( $2.5 \mathrm{~cm}$ inner diameter; $30 \mathrm{~cm}$ length). The column was packed with $31 \mathrm{~g}$ of Ca-alga resulting in a bed height of $23.5 \mathrm{~cm}$. Barium solution $\left(\left[\mathrm{Ba}^{2+}\right]_{\text {feed }}=200 \mathrm{mg} / \mathrm{L}\right)$ was pumped up through the column $(3 \mathrm{~mL} / \mathrm{min}$ in upward flow). Column elution was performed with $1.0 \mathrm{M} \mathrm{HCl}$ solution (37\%, Química Moderna), in downflow $(6 \mathrm{~mL} / \mathrm{min})$. Samples were collected at predetermined time intervals and analyzed by AAS. A dynamic mass transfer model, considering the equilibrium given by the mass action law, a stagnated film and intraparticle mass transfer resistances, was used to predict the kinetic profiles for all species in a packed bed column. Equations (1), (2), (3), (4) and (5) represent, respectively, the mass balances in the liquid phase and initial and boundary conditions.

$$
\begin{aligned}
& \frac{\partial C_{b, n}}{\partial t}=D_{a x} \frac{\partial^{2} C_{b, n}}{\partial z^{2}}-u_{i} \frac{\partial C_{b, n}}{\partial z}-\frac{(1-\varepsilon)}{\varepsilon} \cdot \frac{\rho_{a p}}{f} \frac{d\left\langle q_{n}\right\rangle}{d t} \\
& k_{f, n} a_{p}\left[C_{b, n}-C_{f, n}\right]=\frac{\rho_{a p}}{f} \frac{d\left\langle q_{n}\right\rangle}{d t} \\
& \frac{d\left\langle q_{n}\right\rangle}{d t}=k_{p, n} a_{p}\left[q_{n}^{*}-\left\langle q_{n}\right\rangle\right] \\
& t=0 ; C_{b, n}=0 ;\left\langle q_{n}\right\rangle=q_{n_{0}} \\
& t>0 ;\left\{\begin{array}{l}
z=0 ; \quad C_{b, n}=C_{f e e d, n} \\
z=L ; \frac{\partial C_{b, n}}{\partial z}=0
\end{array}\right.
\end{aligned}
$$



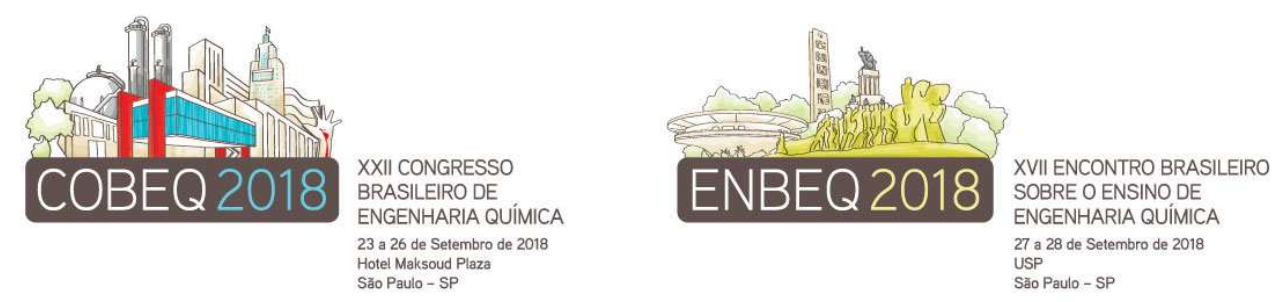

where $C_{b, n,} C_{f, n}$ and $C_{f e e d, n}$ are, respectively, the concentration of species $n\left(\mathrm{Ba}^{2+}, \mathrm{H}^{+}\right.$or $\left.\mathrm{Ca}^{2+}\right)$ in the liquid phase, stagnant film and feed (mEq/L); $t$ is the time (min), $D_{a x}$ is the axial dispersion coefficient $\left(\mathrm{cm}^{2} / \mathrm{s}\right), z$ is the bed axial position $(\mathrm{cm}), u_{i}$ is the interstitial fluid velocity $(\mathrm{cm} / \mathrm{min}), \varepsilon$ is the bed porosity, $\rho_{a p}$ is the particle density $(\mathrm{g} / \mathrm{L}$, dry basis), $f$ is the swelling factor, $q_{n}{ }^{*}$ is the equilibrium concentration, and $\left\langle q_{n}\right\rangle$ is the average concentration of species $n$ at the solid phase, $k_{f, n}$ and $k_{p, n}$ are, respectively, the mass transfer resistance coefficients for species $n$ in the film and for intraparticle diffusion $(\mathrm{cm} / \mathrm{s}), a_{p}$ is the particle specific area $(1 / \mathrm{cm})$.

\section{RESULTS AND DISCUSSION}

Figure 1(a) shows that the maximum biosorption capacity for $\mathrm{Ba}^{2+}$ using $\mathrm{Ca}$-alga at $\mathrm{pH}$ 5.3 was $1.8 \mathrm{mEq} / \mathrm{g}$. The mechanistic model, based on the mass action law, was able to fit satisfactorily the equilibrium data for the ternary mixture $\left(\mathrm{Ba}^{2+} / \mathrm{H}^{+} / \mathrm{Ca}^{2+}\right)$. The selectivity coefficients obtained were $K_{H}^{B a}=6.88$ and $K_{H}^{C a}=3.08$ for carboxylic group and, $K_{H}^{B a}=0.41$ and $K_{H}^{C a}=0.03$ for sulphonic groups. According to Figure 1(b), the barium ions removal takes place by the release of calcium ions, initially bound to the functional groups present at the biomass surface, which indicates that the binding mechanism is an ion exchange process. The stoichiometric ratio between the $\mathrm{Ca}^{2+}$ (algal surface) and the $\mathrm{Ba}^{2+}$ (aqueous solution) is $1: 1$. The $\mathrm{pH}$ rose from 5.3 to 5.6, suggesting the uptake of small amounts of protons. Removal of $\mathrm{Ba}^{2+}$ ions is faster at the initial stage and gradually decreases with time until saturation (250 min). The proposed mass transfer model predicted well the kinetic profiles for all chemical species in the liquid and solid phases (Figure 1(b)).

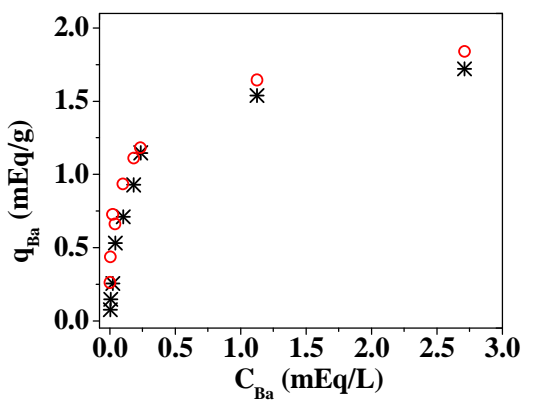

(a)

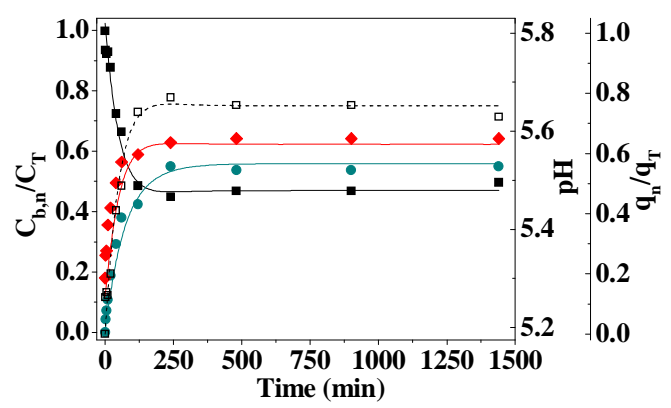

(b)

Figure 1 - (a) Equilibrium experimental data $(*)$ and model prediction $(\circ)$. (b) Kinetic experimental data (points) and model fittings (lines) for barium ion exchange: $C_{\mathrm{Ba}}(\mathbf{\square}), C_{\mathrm{Ca}}$ $(\bullet), \mathrm{pH}(\diamond)$ and $q_{\mathrm{Ba}}(\square) . C_{\mathrm{T}}$ (overall concentration of species in the liquid phase $(\mathrm{mEq} / \mathrm{L})$ ). $q_{\mathrm{T}}$ (overall amount of species sorbed per sorbent mass unit $(\mathrm{mEq} / \mathrm{g})$ ).

Fig. 2a shows the breakthrough curves for all species in the liquid phase using a packed bed column. The length of the mass transfer zone $\left(L_{M T Z}\right)$ was $10 \mathrm{~cm}$ (below the bed length $(23.5$ $\mathrm{cm})$, resulting in a fraction of unused bed length $\left(f_{L U B}\right)$ of $21 \%$. The total capacity was near 1.8 $\mathrm{mEq} / \mathrm{g}(\sim 127 \mathrm{mg} / \mathrm{g} ; 558 \mathrm{BV})$ which is in agreement with batch results. The bed packed with Ca-alga was able to treat $14.2 \mathrm{~L}$ of solution until reaching the breakthrough point, corresponding to a service capacity of $237 \mathrm{BV}$. The barium breakthrough point $(5 \mathrm{mg} / \mathrm{L})$ was established according to the CONAMA's discharge limit (Brazilian Legislation). The bed elution process occurred rapidly in the first $50 \mathrm{~min}$ of operation, corresponding to $96 \%$ elution using $5 \mathrm{BV}$ of 

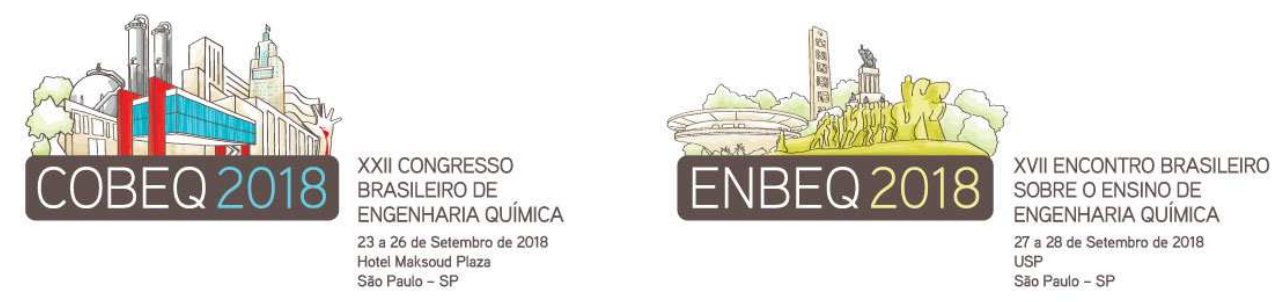

1.0 M HCl in counter-flow direction (Figure 2(b)). The dynamic mass transfer model, presented in section 2, was able to predict satisfactorily the kinetic profile for all species in the continuous system, during saturation and elution steps.

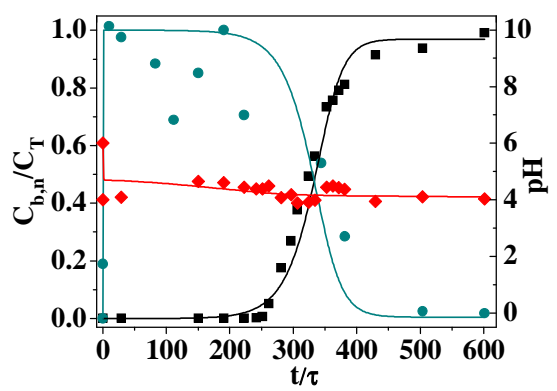

(a)

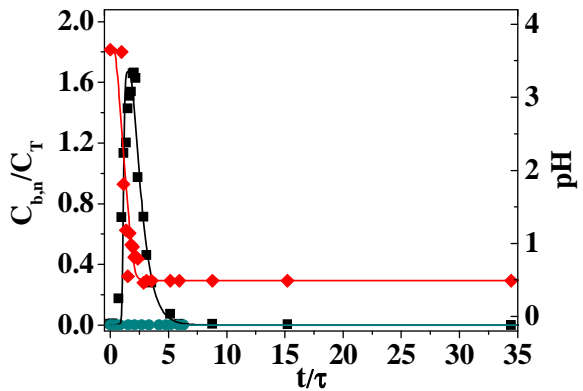

(b)

Figure 2 - Ion exchange column breakthrough curves for barium removal from aqueous solution: (a) saturation and (b) elution. Experimental: $C_{\mathrm{Ba}}(\boldsymbol{\bullet}), C_{\mathrm{Ca}}(\bullet)$ and $\mathrm{pH}(\diamond)$. Model lines: $C_{\mathrm{Ba}}(-), C_{\mathrm{Ca}}(-)$ and $\mathrm{pH}(-)$.

\section{CONCLUSIONS}

The results obtained in this study indicate the $P$. canaliculata as a potential biosorbent for efficient barium removal. The mass action law model successfully fitted the ion exchange equilibrium data for the Ca-loaded $P$. canaliculata with the selectivity coefficients $K_{H}^{B a}=6.88$ and $K_{H}^{C a}=3.08$ for carboxylic groups and $K_{H}^{B a}=0.41$ and $K_{H}^{C a}=0.03$ for sulphonic groups. The service capacity for the fixed-bed system was $237 \mathrm{BV}$, being able to treat $14.2 \mathrm{~L}$ of influent until the breakthrough point. Column elution was fast and efficient. The proposed mathematical mass transfer models satisfactorily described the experimental data for the batch and the fixedbed column configurations.

\section{REFERENCES}

CECHINEL, MAP, MAYER DA, POZDNIAKOVA TA, MAZUR LP, BOAVENTURA AR, SOUZA AA, SOUZA SMAGU, VILAR VJP. Removal of metal ions from a petrochemical wastewater using brown algae as natural cation-exchangers. Chem. Eng. J, v. 286, p. 1-15, 2016.

HACKBARTH FV, GIRARDI F, SOUZA SMAGU, SOUZA AAU, BOAVENTURA AR, VILAR VJP. Marine algae Pelvetia canaliculata (Phaeophyceae) as a natural cation exchanger for cadmium and lead ions separation in aqueous solutions. Chem. Eng. J, v. 242, p. 294-305, 2014.

MAZUR LP, POZDNIAKOVA TA, MAYER DA, SOUZA SMAGU, BOAVENTURA AR, VILAR VJP. Cation exchange prediction model for copper binding onto raw brown marine macro-algae Ascophyllum nodosum: Batch and fixed-bed studies. Chem. Eng. J, v. 316, p. 255276, 2017.

ZERAATKAR, AK, AHMADZADEHA H, TALEBI AF, MOHEIMANI NR, MCHENRY MP. Potential use of algae for heavy metal bioremediation, a critical review. J. Environ. Manage, v. 181, p. 817-831, 2016. 